\title{
COMPREENDENDO NARRATIVAS SOBRE SUICÍDIO COM BASE NA ANALÍTICA EXISTENCIAL DE MARTIN HEIDEGGER ${ }^{1}$
}

\author{
Understanding Self-Reports on Suicide Based on Martin Heidegger's Existential Analytic \\ Entendiendo los auto-informes sobre el suicidio con base en la Analítica Existencial de \\ Martin Heidegger
}

Marcelo Vial Roehe

ELZA DuTRA

\begin{abstract}
Resumo: O artigo apresenta uma proposta de aproximação entre narrativas sobre suicídio e a Analítica Existencial do filósofo alemão Martin Heidegger. A Analítica heideggeriana é uma descrição fenomenológica do modo de ser humano, cujas estruturas ontológicas são consideradas como condição para manifestação de fenômenos específicos, como, por exemplo, o suicídio. Tendo em vista a Analítica de Heidegger, entende-se que o que as pessoas fazem é um desdobramento de suas possibilidades de ser. Foram entrevistados familiares de suicidas e pessoas residentes em cinco municípios do Estado do Rio Grande do Norte, Brasil. Os colaboradores da pesquisa, em número de 20, foram selecionados intencionalmente, conforme os objetivos do estudo. Os depoimentos, em forma de narrativas, foram gravados e transcritos. Posteriormente, foram compreendidos com base na Analítica Existencial de Heidegger. A discussão relaciona o suicídio com a frustração das possibilidades de ser-no-mundo e com o sofrimento correlato a uma existência irrealizada.

Palavras-chave: Suicídio; Narrativa; Analítica existencial; Heidegger.

Abstract: The article presents findings concerning a study, which aims to relate narratives about suicide and Martin Heidegger's Existential Analytic. The heideggerian Analytic is a phenomenological description of the human mode of being, whose ontological structures are considered as a condition to specific phenomena manifestation, e.g., suicide. Adopting a heideggerian point of view, it is understood that what people do is a consequence of their possibilities of being. Twenty people from Brazilian state Rio Grande do Norte five cities with highest suicide rates were interviewed. The subjects are suicidal's relatives and friends whose interviews were recorded and transcribed in narrative form. Based on Heidegger's Existential Analytic, the discussion pointed to the blockage imposed upon the possibilities inherent in being-in-the-world and the suffering related to an unfulfilled existence. Keywords: Suicide; Narrative; Existential analytic; Heidegger.

Resumen: El artículo presenta datos relativos a un estudio cuyo objetivo es relacionar las narrativas sobre el suicidio con la Analítica Existencial de Martin Heidegger. La Analítica heideggeriana es una descripción del modo humano de ser, cuyas estructuras ontológicas se consideran como condición para la manifestación de fenómenos específicos, como el suicidio. Teniendo en vista la Analítica de Heidegger se entiende que lo que una persona hace es consecuencia de sus posibilidades para ser. Veinte personas seleccionadas intencionalmente de acuerdo con los objetivos del estudio fueron entrevistadas. Son habitantes de las cinco ciudades con más altos índices de suicidio en el estado del Rio Grande do Norte. Entre ellos hay parientes y amigos de suicidas. Las entrevistas fueron grabadas y transcritas en forma narrativa. Basado en la Analítica de Heidegger, la discusión apunta a la obstrucción impuesta sobre las posibilidades inherentes en el ser-en-el-mundo y el sufrimiento relacionado a una existencia sin cumplir.
\end{abstract}

Palabras clave: Suicidio; Narrativa; Analítica existencial; Heidegger.

\section{Considerações iniciais \\ 1}

Relatório recentemente publicado pela World Health Organization (WHO, 2014), a respeito de prevenção do suicídio, trata como um mito a ideia de que se deve evitar falar sobre suicídio, pois a divulgação poderia funcionar como um estímulo ou um encorajamento a sua prática. Ao contrário, afirma a WHO (2014): como o suicídio é amplamente estigmatizado, a maioria das pessoas que pensa em cometê-lo não sabe com quem falar. Falar abertamente sobre o suicídio pode oferecer ao indivíduo outras opções

${ }_{1}$ Pesquisa realizada com apoio do CNPq. ou tempo para repensar sua decisão e, assim, possibilitar a prevenção do suicídio.

Os dados mais recentes da WHO, de 2012, mostram uma taxa de 5.8 casos de suicídio por 100.000 habitantes no Brasil. Um aumento de $10.4 \%$ em relação aos dados do ano 2000. Para cada mulher, 3 a 4 homens cometem suicídio no Brasil. Entretanto, entre as mulheres a taxa de suicídio cresceu o dobro da dos homens, no período 2000-2012. Em números absolutos, o Brasil é o oitavo país com mais mortes por suicídio. Já em casos por 100.000 habitantes, está abaixo da média mundial, que é de 11.4.

Mundialmente, são mais de 800.000 casos de suicídio por ano, sendo a segunda causa principal de morte 
na faixa etária entre 15-29 anos (WHO, 2014). O relatório da WHO estima que para cada adulto morto por suicídio, outros 20 podem ter tentado suicídio. Países com nível econômico de médio para baixo concentram 75\% dos casos de suicídio (WHO, 2014).

Na América Latina, 35000 suicídios são registrados anualmente, sendo que as taxas mais altas são as de Guiana e Suriname (15/100000), seguidos por Uruguai e Chile. Considerando-se os dados apresentados até esse momento, constata-se a importância de se aprofundar os estudos acerca desse fenômeno, inclusive no Brasil, ainda que a estatística do suicídio no país não se equipare àquelas mais altas, verificadas em outros países (WHO, 2014).

Botega, Marin-León, Oliveira, Barros, Silva \& Dalgalarrondo (2009) estimam que de cada 100 pessoas, 17 terão algum tipo de pensamento suicida durante sua vida; destas, 5 chegarão a planejar, 3 a realizar alguma tentativa e 1 precisará de atendimento hospitalar. Conforme publicação do Ministério da Saúde do Brasil (2006), os fatores de risco para o suicídio abrangem: transtornos mentais, como depressão, transtornos de ansiedade e personalidade borderline; fatores sociodemográficos, como desemprego, isolamento social, faixas etárias entre 15 e 35 anos e acima de 75 e fatores psicológicos, como perdas recentes, perdas de figuras parentais na infância, dinâmica familiar conturbada e datas importantes; além disso, existem as condições clínicas incapacitantes, como dor crônica, lesões desfigurantes perenes, trauma medular e neoplasias malignas.

Ainda que os fatores de risco e os sinais de alerta tenham sido extensivamente investigados, Fowler (2012) afirma que não há ferramentas diagnosticas que permitam antecipar o ato suicida, devido à complexidade do fenômeno, cuja natureza fluida, mutável é altamente influenciada pela situacionalidade. Jamison (2000) escreve que, apesar do vasto conhecimento já produzido acerca do suicídio, ainda há deficiência quanto a por que alguém se mata. A autora afirma que se já é difícil verificar estados psicológicos, motivação complexa e sutis diferenças biológicas entre os vivos, mais ainda é entre os mortos.

A palavra suicídio (do latim, sui=de si, a si, próprio; caedere=bater, golpear, matar) surgiu no século XVII e passou a ser utilizada com mais frequência a partir de 1734, quando aparece nos escritos dos abades franceses Prévost e Desfontaines (Palhares \& Bahls, 2003). Durkheim (1992) no clássico O Suicídio define suicídio como: "todo o caso de morte que resulta direta ou indiretamente de um ato positivo ou negativo praticado pela própria vítima, ato que a vítima sabia dever produzir este resultado” (p. 10).

Ao longo da história, a questão do suicídio foi considerada de diferentes maneiras, de acordo com o tempo, o espaço e a cultura. Foi considerado ato altruísta ou indicador de insanidade; foi alvo de julgamento, e a família do suicida poderia ser punida (Alvarez, 1999; Palhares \& Bahls, 2003). Em determinado período da antiguidade grega e romana, o suicídio era aceito somente se autori- zado pelo Estado (Serra, 2008). Durkheim (1992) cita um autor ateniense da época, que descreve o procedimento para a autorização do suicídio:

Que aquele que não quer viver mais tempo exponha as suas razões ao Senado e deixe a vida se o Senado lhe der autorização para partir. Se a existência te é odiosa, morre; se o destino te é opressivo, bebe a cicuta. Se o peso da dor te faz andar curvado, abandona a vida. Que o infeliz relate os seus infortúnios, que o magistrado lhe forneça o remédio e a miséria cessará. (Libanius citado em Durkheim, 1992, p. 329)

Sêneca (4 a.C. - 65 d.C.), o estóico romano, via o suicídio como uma opção legítima do homem:

Homem tolo, de que te lamentas e de que tens medo? Para onde quer que olhes existe um fim para os males. Vês aquele precipício escancarado? Ele leva à liberdade. Vês aquele oceano, aquele rio, aquele poço? A liberdade mora dentro deles. Vês aquela pobre árvore mirrada e seca? De cada galho seu pende a liberdade. Teu pescoço, tua garganta, teu coração, todos oferecem tantos meios para fugir da escravidão [...] Indagas o caminho para a liberdade? Tu o encontrarás em cada veia do teu corpo. (Sêneca citado em Palhares \& Bahls, 2003, p. 29)

Para Dutra (2010), o suicídio, ainda nos dias atuais, segue envolto numa aura de pecado, vergonha e preconceito, assim como na Inglaterra do século XVII, em que o corpo do suicida era atravessado por uma estaca e colocado numa encruzilhada, com uma pedra na cabeça, de modo que não voltasse para assombrar os vivos. Por outro lado, a autora confirma a variabilidade das posturas diante do suicídio, referindo a prática japonesa do haraquiri, o suicídio honroso. Dutra (2010) alerta que o suicídio não é necessariamente causado por psicopatologia. A autora entende que a cultura imediatista e capitalista contemporânea rejeita a angústia, a tristeza e o mal-estar que, inevitavelmente, acompanham a vida e exige competência, agilidade e jovialidade facilitando, deste modo, que pessoas não "encaixadas" nesta visão de mundo venham a ser consideradas doentes. A patologização do suicídio, observa Dutra (2010), reforça estigmas e preconceito contra quem o pratica e protege do mal-estar de pensar que o suicídio pode, sim, ser pensado como uma alternativa viável para a vida e resultar de uma decisão racional. Adotando uma visão ampliada de saúde, Dutra (2010) ressalta que as características socioeconômicas do contexto onde ocorre o suicídio não devem ser ignoradas:

(...) não podemos ignorar o fato de que uma sociedade que exclui os cidadãos do sistema educacional e de saúde e que elimina as oportunidades de uma melhor qualidade de vida é também uma sociedade que 
favorece a perda de sentido de vida e, desse modo, reforça, em algumas pessoas, o desejo de não mais viver. (p. 246)

O presente artigo propõe uma aproximação entre depoimentos sobre suicídio e a Analítica Existencial de Martin Heidegger. Foram realizadas entrevistas com parentes e amigos de suicidas e com moradores das cidades selecionadas para o estudo. Entrevistando pessoas ligadas aos suicidas, a pesquisa vai ao encontro da necessidade de mais estudos acerca do impacto do suicídio em familiares e pessoas próximas (Cerel, Jordan \& Duberstein, 2008). Aqueles que perdem um parente ou amigo devido ao suicídio são chamados "sobreviventes" e estão sujeitos a considerável sofrimento, problemas mentais e mesmo tentativas de suicídio (Cerel, Jordan \& Duberstein, 2008).

Além disso, é objetivo do estudo relacionar o fenômeno suicídio com as estruturas do modo de ser humano, apresentadas por Heidegger (1927/2006), levando-se em consideração que, independentemente de uma condição patológica, suicidar-se é uma possibilidade inscrita na constituição existencial do homem. Quais aspectos do Dasein heideggeriano se apresentam em relevo, quando se questiona o suicídio? As respostas obtidas nesse estudo dizem respeito a um contexto restrito, entretanto a relação estabelecida com as estruturas do Dasein permite pensar o suicídio de modo mais amplo, naquilo que o fenômeno tem de relação com a constituição existencial do ser humano.

\section{A Analítica do Dasein}

Em sua obra fundamental, Ser e Tempo, publicada em 1927, Martin Heidegger (1927/2006) se propôs a elaborar uma ontologia fundamental. Num vocabulário simplificado, pode-se dizer que o filósofo pretendia mostrar como tudo começa. Tudo o quê? Tudo o que é. O que "é” aparece no modo de ser do homem, o qual se diferencia do modo de ser dos demais entes por ter uma compreensão do ser. É a partir da compreensão do ser - vaga, mediana - que distingue o ser humano - permitindo-lhe, portanto, dizer "é” - que Heidegger inicia o questionamento do ser ou, nas palavras de Aho (2009): "como e por que os entes aparecem do modo como aparecem” (p. 8).

Entendendo que a tradição metafísica grego-teológica define o homem como uma coisa simplesmente dada (criatura animal racional), ignorando a questão de seu ser, Heidegger denomina Dasein (literalmente, "Ser-aí”; na versão brasileira de Ser e Tempo, "Presença”) ao modo de ser do ente que nós mesmos somos. Denominações como "homem”, "sujeito", "animal racional” são produto do pensamento metafísico, ao qual o filósofo coloca em questão. Com os próprios termos empregados, Heidegger pretende rever a tradição metafísica, cuja linguagem carrega consigo as consolidações que o filósofo visa evitar.
Dasein quer dizer ser aberto para o ser, de modo a encontrar a si mesmo e aos demais entes:

o Da em Ser e Tempo não significa a definição de um lugar para um ente, mas deve indicar a abertura onde os entes podem estar presentes para o ser humano e o próprio ser humano presente para si mesmo. (Heidegger, 1987/2001, p. 120)

A descrição do modo de ser humano que Heidegger realiza mostra que o homem está em relação com seu próprio ser, ou seja, o ser do homem é uma questão para ele mesmo, porém não - na maior parte do tempo - uma questão racional que gera uma resposta, uma conclusão, trata-se de uma questão/relação com o próprio ser que se "conclui" apenas provisoriamente no fazer cotidiano da existência: "Ser é o que neste ente está sempre em jogo" (Heidegger, 1927/2006, p. 85). Estando sempre em jogo, sempre em questão, na própria existência, a essência do ser humano está em "ter de ser". Ou seja, "a presença se entrega à responsabilidade de assumir seu próprio ser" (Heidegger, 1927/2006, p. 85).

As características constitutivas do ser do homem não são propriedades identificadas na matéria, como no caso dos entes naturais (a rigidez de uma rocha, por ex.), mas sim "modos possíveis de ser e somente isso" (Heidegger, 1927/2006, p. 85). A esse modo de ser, o modo de ser do Dasein, Heidegger (1927/2006) chama existência: “chamamos existência ao próprio ser com o qual a presença pode relacionar-se dessa ou daquela maneira e com o qual ela sempre se relaciona de alguma maneira" (p. 48). Sendo assim, "existência" é um termo que designa exclusivamente o ente humano: todos os entes "são", mas apenas o $D a$ sein existe. O Dasein apresenta uma constituição na qual Heidegger identifica diferentes estruturas existenciais cuja manifestação é simultânea, "equiprimordial”. O primeiro constituinte descrito por Heidegger é o ser-no-mundo:

A expressão composta “ser-no-mundo", já na sua cunhagem, mostra que pretende referir-se a um fenômeno de unidade. Deve-se considerar este primeiro achado em seu todo. A impossibilidade de dissolvê-la em elementos, que podem ser posteriormente compostos, não exclui a multiplicidade de momentos estruturais que compõem esta constituição. (Heidegger, 1927/2006, p. 98-99)

Conforme Heidegger, ser humano e mundo aparecem como unidade originária: não há homem sem mundo, nem mundo sem homem. O ser humano não entra em relação com o mundo a partir de sua racionalidade primária, pelo contrário, a racionalidade é que se desenvolve desde o vínculo original do homem com os demais entes. Não há um "Eu" autossuficiente, cujo modo de ser prescinda dos demais entes ou cuja autocompreensão se desenvolva sem a identificação com as ocupações cotidianas e as 
preocupações com os outros. Vattimo (1971/1987) elabora esta noção:

O ser-no-mundo nunca é um sujeito puro, porque nunca é um expectador desinteressado das coisas e dos significados; o projeto dentro do qual o mundo aparece ao dasein não é uma abertura da razão como tal, mas sempre um projeto qualificado, definido, poderíamos dizer, tendencioso. (p. 54)

O Dasein é envolvido no mundo, é interessado, em função de outra estrutura existencial, a disposição afetiva. A disposição diz respeito a como alguém está, “como vai”. O ser humano não existe num estado neutro diante da realidade, pelo contrário, o que se mostra na abertura do aí já aparece vinculado a uma tonalidade afetiva. As coisas do mundo, os outros e o seu próprio ser fazem diferença para o Dasein, podem tocá-lo de alguma maneira, ainda que na forma de desinteresse ou desimportância.

Como alguém está implica um contexto do qual necessariamente fazemos parte, implica "estar". O ser humano não conduz a si mesmo até o ser: ele é lançado (ser-lançado) no mundo como herdeiro de condições históricas e ideológicas, herdeiro de uma compreensão mediana da existência num determinado período (Sheehan, 1995). Ser-lançado e, com isso, não poder retroceder e se apropriar do próprio ser desde o princípio, corresponde à facticidade do Dasein. Sendo-lançado, o Dasein já se encontra situado, já se encontra envolvido em relações com outros entes. Já sempre situado, contextualizado, o Dasein sempre compreende o ser em geral e o seu próprio ser de alguma maneira. Esta compreensão não é um conhecimento teórico, racional. Ela é prática, porque é relativa ao modo de ser (verbo, ação).

Em todo comportamento em relação ao ente, quer se trate especificamente de conhecimento, o que na maioria das vezes se designa como teórico, quer se trate de um comportamento técnico-prático, já se encontra uma compreensão de ser. Pois só sob à luz da compreensão de ser um ente pode vir ao nosso encontro como ente. (Heidegger, 2012, p. 400)

A compreensão se mostra naquilo que o ser humano faz, no lidar com a própria existência, providenciar algo "em virtude de" possibilidades mundanas. Heidegger (1927/2006) observa: "O que se pode no compreender, assumido como existencial, não é uma coisa, mas o ser como existir. Pois no compreender subsiste, existencialmente, o modo de ser da presença como poder-ser" (p. 203). O Dasein existe sempre em função de um poder-ser que, embora ainda não realizado, já o caracteriza de fato. O futuro (porvir) está sempre implicado, constitui as ações (presentes), uma vez que o ser humano antecede-a-si-mesmo (Heidegger, 1927/2006).
Em seu ser, a presença já sempre se conjugou com uma possibilidade de si mesma (...) já sempre antecedeu a si mesma. A presença já está sempre 'além de si mesma', não como atitude frente aos outros entes que ela mesma não é, mas como ser para o poder-ser que ela mesma é. (Heidegger, 1927/2006, p. 258-259)

O ser-possível do Dasein se realiza nos três modos de relações que o constituem: com entes não humanos, com entes humanos e consigo mesmo. Ou, segundo Heidegger (1927/2006): “a possibilidade essencial da presença diz respeito aos modos caracterizados de ocupação com o "mundo", de preocupação com os outros e, nisso tudo, à possibilidade de ser para si mesma” (p. 203). Heidegger (1927/2006) rejeita o entendimento do ser humano como uma unidade isolada que, por proximidade espacial, se agrupa com outros seres humanos. Para o filósofo, o homem - existencialmente, ontologicamente - se distingue pela convivência, pelo ser-com; o mundo do homem é mundo compartilhado. Ser-homem sempre envolve a presença de outros homens. O ser humano sempre está referido a um contexto familiar, um ambiente de trabalho, uma localização (rua, bairro, cidade, etc.), uma origem (povo, país), o uso de objetos comuns produzidos por outras pessoas; todas são determinações coletivas que contribuem para o desenvolvimento de nossa própria identidade (nosso nome, por ex., é decidido por outros). A convivência é uma característica do Dasein e sua realização poderá ser plena ou deficiente, habilidosa ou difícil, quer dizer, a maneira ou a qualidade com que exercitamos o ser-com são possibilidades de um modo de ser já constituído no mundo compartilhado. Heidegger (1927/2006) usa o termo preocupação para designar, de forma geral, os relacionamentos possíveis entre seres humanos. "O ser-com determina existencialmente a presença, mesmo quando um outro não é, de fato, dado ou percebido. Mesmo o estar-só da presença é ser-com no mundo. Somente num ser-com e para um ser-com é que o outro pode faltar" (Heidegger, 1927/2006, p. 177).

Só pode ser solitário ou viver isolado quem, originalmente, é social. Quando se percebe que alguém está "falando sozinho", isso somente chama a atenção porque a fala é sempre entendida como ato comunicativo exigindo, portanto, comunidade. A fala é relativa a uma "convivência ocupacional” e dela fazem parte a escuta e o silêncio. "Escutar é o estar aberto da presença enquanto ser-com os outros" (Heidegger, 1927/2006, p. 226). O Dasein é antecedendo-a-si-mesmo na forma de compreensões já projetadas e neste movimento existencial ele encontra sua possibilidade derradeira, a morte. Ser-para-a-morte é como Heidegger chama este modo de ser do Dasein. A morte aqui não é vista como um evento que está por vir ou como o final da vida instalado num ponto futuro ao qual se deve chegar; o Dasein é ser-para-o-fim: sendo para sua morte, ele, de fato, morre constantemente enquanto existe. O fim, como possibilidade, acompanha o Dasein desde o início. A morte também não é um evento 
que completa a vida do ser humano: como poder- ser, o Dasein sempre é possibilidade, ou seja, enquanto existe, ele ainda-não é o que pode ser. O ser humano, "enquanto existir, deve, em podendo ser, ainda não ser alguma coisa” (Heidegger, 1927/2006, p. 305).

Em Ser e Tempo, a morte como ser-para-o-fim é vista como a possibilidade mais própria do Dasein, pois é ele mesmo que "dá a si” essa possibilidade. A morte, como possibilidade própria, não está nas relações do ser-com ("preocupação" com os outros), nem no lidar com os entes não humanos ("ocupação" com as coisas). A morte é de si mesmo para si mesmo. Ela é singular como possibilidade para o Dasein e singulariza o Dasein como possibilidade irremissível de si mesmo. Sendo-para-a-morte, o ser humano somente pode apreender a morte como um fenômeno antecipatório. Não se tem a experiência da morte mesma, uma vez que, na morte, cessam as experiências. Enquanto se vive, antecipa-se a morte como a possibilidade (certa) do fim.

À totalidade estrutural do ser do Dasein, Heidegger (1927/2006) chama de cura. Como estrutura existencial, a cura mostra a unidade do anteceder-a-si-mesmo, do ser-em (facticidade) e do ser-junto aos demais entes: antecedendo-a-si-mesmo, o ser humano se projeta em possibilidades, a partir da situação em que ele já está e vem sendo, enquanto se preocupa com outros seres humanos e se ocupa com entes não humanos. Heidegger enfatiza que determinar o modo de ser do Dasein como cura não implica priorizar a atitude prática ao invés da teórica, ambas são possibilidades do Dasein como cura. O filósofo também afirma a indivisibilidade do fenômeno, observando que a cura não se refere a ações ou impulsos específicos como querer, desejar ou tender. Nos momentos constitutivos da cura, aparece a temporalidade do modo de ser humano: antecede-se (futuro), desde onde já se está (passado), a fim de lidar com o que vem ao encontro no mundo (presente).

Safranski (2005) ressalta a importância da temporalidade na cura. Para o autor, cura é "temporalidade vivida”, ou seja, ter "diante de si um horizonte temporal aberto e indisponível no qual tem de viver" (p. 198). Borges-Duarte (2010) entende a cura como "inquieta atenção e tensão vital, que gere esforçada e, tantas vezes, molesta o viver, que o tempo marca e determina” (p. 120). Conforme Polt (1999), ser como cura significa que seu próprio ser e o ser dos demais entes fazem diferença para o homem; Polt entende que se trata de uma reprovação implícita de Heidegger às filosofias que isolam o homem do tempo e do espaço: "não há como evitar o enraizamento num passado e o enfrentamento de um futuro" (Polt, 1999, p. 79).

\section{Método}

Trata-se de uma pesquisa qualitativa, de orientação fenomenológico-existencial. $\mathrm{O}$ aspecto fenomenológico diz respeito a como o entrevistado significa e comunica sua experiência sobre o que lhe foi questionado; de modo que esta comunicação é tomada como fenômeno (aquilo que se mostra) pelo pesquisador. $\mathrm{O}$ aspecto existencial é relativo ao modo de ser humano, entendido de acordo com a Analítica heideggeriana. Assim, o que é comunicado é uma possibilidade do ser humano e está ancorado nas estruturas do Dasein, as quais se revelam na comunicação.

A estratégia metodológica utilizada para a coleta de dados foi a narrativa, tal como proposta por Dutra (2002) e Schmidt (1990). Trata-se de uma entrevista semi-aberta iniciada com uma pergunta disparadora que permita ao entrevistado começar uma fala sobre o fenômeno questionado, em seus próprios termos. Schmidt (1990) observa que

A narrativa é preciosa, pois conecta cada um à sua experiência, à do outro e à do antepassado, amalgamando o pessoal e o coletivo. E o faz de uma maneira democrática ou, mais precisamente, da única maneira possível para que uma prática social seja democrática - fazendo circular a palavra, concedendo a cada um e a todos o direito de ouvir, de falar e de protagonizar o vivido e sua reflexão sobre ele. (p. 51)

Aos entrevistados foi perguntado, inicialmente, o que ele poderia dizer sobre a experiência de perder um familiar por suicídio ou, quando o colaborador não era familiar do suicida, perguntou-se o que ele pensava sobre o suicídio ou o que ele pensava que poderia levar uma pessoa a cometer suicídio. As entrevistas foram gravadas e transcritas; posteriormente, foi feita uma leitura detalhada da narrativa, visando identificar falas e significados que revelem características da vivência questionada. Este procedimento deu origem a alguns temas que foram interpretados levando-se em consideração as demais narrativas e o referencial teórico.

Foram entrevistadas 20 pessoas residentes em cinco cidades do interior do Rio Grande do Norte, quatro em cada município, entre familiares dos agricultores suicidas e moradores das cidades. As cidades foram escolhidas entre aquelas detentoras das mais altas taxas de suicídio entre agricultores (Dutra, 1997). Os pesquisadores foram aos endereços dos familiares dos suicidas; os endereços foram obtidos junto ao Instituto Técnico de Polícia do Rio Grande do Norte (ITEP). Os pesquisadores se apresentaram, informaram sobre os objetivos da pesquisa e consultaram a respeito de sua disponibilidade para conceder entrevista. A partir do contato inicial com familiares, obteve-se indicações de outras pessoas que poderiam ser entrevistadas, uma vez que o objetivo dos pesquisadores foi questionar o fenômeno suicídio em locais de alta incidência, sem priorizar vínculo familiar com os suicidas. Havendo concordância das pessoas abordadas em conceder entrevista, foi apresentado o Termo de Consentimento Livre e Esclarecido. 


\section{Compreensão de trechos das narrativas desde o ponto de vista analítico-existencial}

Excertos de algumas entrevistas exemplificam como a Analítica Existencial de Heidegger pode ser utilizada como referencial para a reflexão sobre o fenômeno do suicídio. Parte-se do princípio de que fenômenos humanos são manifestações do modo de ser do homem. Estas manifestações, no entanto, não são compulsórias, são possíveis. Em outras palavras: o homem, em seu modo de ser, apresenta características que lhe permitem, por exemplo, suicidar-se, assim como lhe permitem matar outra pessoa. O modo de ser do homem também lhe permite gostar de nadar ou ser psicólogo, jogador de futebol, enfim, aquilo que o ser humano manifesta são possibilidades que, como tal, já estão dadas na constituição de seu modo de ser, entendido neste artigo como Dasein, nos termos de Heidegger. Cabe ressaltar que os autores não dispõem de informações a respeito da condição de saúde dos suicidas e somente caracterizam o fenômeno em diálogo com idéias de Heidegger.

Francisca, 39 anos, moradora de uma das cidades visitadas, diz: A pessoa fazer uma coisa dessa, né? E eu sei lá... pela caridade. Só sendo uma pessoa com muito aperreio... aperreada. Querendo que o aperreio acabasse. Aperreio é incômodo, desconforto, aborrecimento. É o que Heidegger (1927/2006) designa disposição afetiva. O ser humano está sempre em relação com o mundo e não se trata de uma relação contemplativa: é uma relação prática (uma relação de “ser”, verbo), pela qual é afetado. As ocupações (com entes não humanos) e as preocupações (com os outros) fazem diferença, "tocam". A condição existencial do Dasein é de ser "determinado previamente em sua existência, de modo a poder ser tocado [...] pelo que vem ao encontro dentro do mundo. Esse ser tocado funda-se na disposição [...]” (Heidegger, 1927/2006, p. 196).

O trecho de entrevista citado a seguir expressa a manifestação da disposição, numa questão sobre o porquê do suicídio:

(...) tem gente que se magoa por qualquer coisa, é frágil de se magoar, tem que se ter um estudo profundo para se entender como é que é isso. A psicologia é um estudo difícil de se entender, porque tem gente que se magoa com qualquer coisa e tem gente que não tá aí com nada, e assim vai. (Marcos, 21 anos, morador)

A qualidade das disposições afetivas é relativa ao que vem ao encontro e como vem. Manifestações dos colaboradores do estudo revelam o entendimento de que as condições de vida nos locais visitados são muito limitadoras e frustrantes:

Aqui não tem emprego não... O meu filho reclamava: (a cidade) tem um nome tão bonito... mas emprego pro povo trabalhar não tem...
Vivemos dessa plantação... de milho... e feijão. $\mathrm{O}$ algodão não dá mais... o bicudo acabou... Recebemos aposentadoria... Não temos televisão... Temos rádio... Passamos o dia assim... plantando... catando... debulhando... Conversando... com os vizinhos... chega os vizinhos... ali tem uma mulher que tem dia que ela passa o dia todinho aqui...só pensando na vida mesmo. A vida sofrida... vida sofrida... é assim... a pessoa viver no sítio trabalhando... a produção esperando por Deus mandar... Ai meu Deus... mas ele só dá as coisinhas fraquinhas assim mesmo... Quando acontece uma seca dessa... num tempo bom, é só chegar a chuva... nós torcemos pra que Deus mande, né? Ficamos esperando a chuva... (Antonio, 56 anos, pai de um suicida)

O ser humano sempre tem uma compreensão de seu próprio ser, ainda que vaga, mediana. Essa compreensão ocorre em meio aos demais entes com os quais se relaciona, em meio aos quais ele sempre está e com os quais se identifica, na maioria das vezes. Heidegger observa que compreender seu próprio ser é projetar-se em possibilidades, as quais se mostram na relação com os demais entes: "No compreender a presença projeta seu ser para possibilidades. Esse ser para possibilidades em compreendendo é um poder-ser que repercute sobre a presença as possibilidades enquanto aberturas" (Heidegger, 1927/2006, p. 209). Não se trata, porém, de um processo cognitivo. É na ocupação com o trabalho agrícola ("plantando", "catando", debulhando") que os entrevistados transcendem a si mesmos e engendram seus projetos. Entretanto, a ocupação em questão fracassa; o ocupar-se é percebido como inútil (espera-se pela ação de Deus, pois a ocupação não produz consequência).

Na medida em que as possibilidades se mostram impossíveis, sua repercussão como abertura se perde e, psicologicamente, pode-se pensar em fechamento ou não-poder-ser ou em "aperreio":

Ai meu Deus é um sofrimento... um sofrimento e grande. Uma pessoa viver aqui meu Deus! Sei lá... num tem um trabalho... num tem nada pra gente... é ruim demais...A vida dos jovens aqui é assim...eles não fazem nada... Nada... vão pro colégio... e pronto. Durante o dia sai pro colégio e fica assim mesmo... sem ter o que fazer... porque não tem o que fazer de jeito nenhum... Sobre a minha vida...sei lá minha filha... com um rebanho de filho eu sofro muito... sem ter condições... penso que é um sofrimento e grande... Tinha vontade de sair daqui... de mudar de vida... Porque pelo menos a pessoa podia arrumar... sei lá... um trabalho... uma coisa... Aqui não tem trabalho não... Os filhos... jovens... os rapazes e moças... pensam em sair daqui... Eu não sei o que é que eles pensam em fazer da vida... (Francisca, 39 anos) 
Quando os entrevistados descrevem suas condições de vida, mostram a relação entre suas possibilidades e o mundo em que, necessariamente, todo ser humano habita. $\mathrm{O}$ relato mostra que o mundo pode se tornar um contexto inóspito (Critelli, 1996) que barra os projetos pessoais (por mais simples que sejam), deixando no horizonte da existência apenas aquilo que Heidegger (1927/2006) chama de "possibilidade da impossibilidade" de si mesmo, a morte. A questão da morte em Heidegger exige considerações que estão além dos objetivos deste artigo. Todavia, é certo que a morte não é uma possibilidade como outra qualquer, algo do tipo "pode ser ou pode não ser", não, a ocorrência da morte é uma certeza. Entretanto, antecipar a própria morte é, sim, uma possibilidade. O fato de que não se sabe quando se vai morrer, permite que, por iniciativa pessoal, decida-se quando será este momento. O suicídio é este momento, em que se exerce a possibilidade de antecipar - e realizar - a própria morte.

$\mathrm{O}$ ato de suicidar-se aparece como uma recusa ao que Heidegger (1927/2006) chama de peso ou carga do ser, uma vez que o homem é ser-lançado no mundo, em condições que não escolheu e tem diante de si possibilidades de vir a ser algo, na medida em que "carregue" seu próprio ser (fazer algo de sua vida, como diz Francisca acima) numa ou noutra direção.

Existindo, a presença é o fundamento de seu poderser porque só pode existir como o ente que está entregue à responsabilidade de ser o ente que ela é. Embora não tendo ela mesma colocado o fundamento, a presença repousa em sua gravidade que, no humor, se revela como peso. (Heidegger, 1927/2006, p. 364, itálicos no original)

Alguns entrevistados, questionados a respeito do motivo que levaria alguém a se matar, disseram que o suicídio seria consequência de uma "fraqueza" da pessoa. Esta é uma maneira de reconhecer que a vida exige força para carregar um peso. A cultura popular reconhece a questão do peso do ser quando manifesta o desejo de que aquele que morreu "descanse em paz". Para Heidegger (1927/2006), o homem existe sempre em função de um poder-ser que, embora ainda não realizado, já o caracteriza de fato. $\mathrm{O}$ futuro está sempre implicado, constitui as ações (presentes), uma vez que o ser humano antecede-a-si-mesmo (Heidegger, 1927/2006).

Em seu ser, a presença já sempre se conjugou com uma possibilidade de si mesma (...) já sempre antecedeu a si mesma. A presença já está sempre 'além de si mesma', não como atitude frente aos outros entes que ela mesma não é, mas como ser para o poder-ser que ela mesma é. (Heidegger, 1927/2006, p. 258-259)

Assim, uma vida que não se realiza, um poder(querer)-ser que não se efetiva carrega a inconformidade com o ser, em outras palavras, é ser o que não se pode ser. O depoimento abaixo, sobre um motivo para o suicídio, se aproxima desse entendimento.

eu acho que o desespero de se ver, olhar, acordar todo o dia de manhã e olhar para um lado e para o outro e não ver perspectiva nenhuma (...) crescer, morrer, e não ver um emprego, não ver desenvolvimento na sua cidade. Cada dia que passa, tudo mais desestruturado... quer dizer, se eu acordo todos os dias e vou imaginar a mesma coisa (...) às vezes muita gente chega a botar isso em mente, já que não tem nada para fazer, em que se ocupar, se imaginar, sem nada no bolso, seu pai e sua mãe sem ter condições de lhe manter. Eu acho que basicamente, isso. Não é que todo mundo vai acontecer, mas também, só chega a esse ponto quem é realmente muito fraco, e não quiser lutar, batalhar. (Daliana, 20 anos, moradora)

A visão do futuro (anteceder-se), porém, pode ser a justificativa para a continuidade da vida e a rejeição do suicídio:

(a pessoa) não deve se suicidar porque tem coisas pela frente, suicídio é uma coisa que a pessoa não deve pensar né? A pessoa não deve pensar em suicídio... que suicídio é uma coisa que não deveria caber na cabeça... a gente não deve se suicidar... deve pensar no futuro... no diante... nas coisas, né? (Bentinho, adolescente, morador)

eu tenho uma resposta para o suicídio para quem precisar, eu tenho essa resposta. Você não pode, você tem que pensar no futuro, o futuro que vai te trazer, o tempo que vai te trazer, vai cobrir as feridas que abriram... (Ana Maria, 16 anos, moradora)

O papel das relações sociais, do outro, foi destacado pelos entrevistados na reflexão sobre o comportamento suicida:

Brigas, confusões, traições, muitas outras coisas como até pessoas, assim, são amigos e se estranham, aí pensam: "meu Deus eu vim pra esse mundo, tenho amigos, e eles não me consideram".

...você se enforcar, os problemas da vida não vai sumir, mas sim vai ficar pras outras pessoas a responsabilidade.

Se tiver namorado e gostar muito e a pessoa lhe der um fora, um marido se separar da mulher e ele não quiser que a mulher viva com outro companheiro, isso tudo leva a suicídio. (Roseane, 12 anos, moradora)

Heidegger (1927/2006) rejeita o entendimento do ser humano como uma unidade isolada que, por proximidade espacial, se agrupa com outros seres humanos. Para o 
filósofo, o homem se caracteriza pela convivência, pelo ser-com; o mundo do homem é mundo compartilhado. Ainda que alguém vivesse completamente isolado, o isolamento indica a referência aos demais. Isolar-se ou viver junto a várias pessoas são possibilidades de um ente cuja relação com os outros é condição de seu modo de ser. Erimar, 21 anos, relata que pensou em cometer suicídio e comenta:

(cometer suicídio)... é uma fraqueza muito forte... assim, eu acho que é falta de amor, ou em casa, nos cantos, graças a Deus eu em casa eu sou muito, como é que se diz, bem amado por meus pais, meus irmãos, a gente tem uma união muito grande, tudo que vamos fazer é em grupo, lá nos escoteiros também tudo que a gente vai fazer, uma festinha, a gente combina com todo mundo, pra ver se dá certo, se não der certo, a gente já combina pra outro dia, e a gente sempre tá ligado uns com os outros... a gente nunca fica só, quando a gente tá triste, porque nós temos uma amizade muito grande, então já se percebe, “tá triste, Por quê?” Mesmo que você esteja rindo, brincando, mas sempre tem um que chega e diz "tá triste por quê? Não, porque eu to notando isso e isso em você.” Geralmente a gente conversa uns com os outros.

Ser-homem, então, sempre envolve a presença de outros homens. A convivência é um aspecto existencial do ser humano e sua realização poderá ser plena ou deficiente, habilidosa ou difícil, quer dizer, a maneira ou a qualidade com que exercitamos o ser-com são possibilidades de um modo de ser já constituído no mundo compartilhado. Heidegger (1927/2006) usa o termo preocupação para designar, de forma geral, os relacionamentos possíveis entre seres humanos.

Sendo assim, caracterizado por ser-com e preocupação, o ser humano pode vivenciar o luto (que é uma disposição afetiva). O que determina o luto não é a morte (fenômeno biológico), porém a perda (fenômeno humano) de alguém que era importante. Gilson, 24 anos, tentou suicídio por intoxicação e enforcamento, relaciona o ser-com e o anteceder-a-si-mesmo, ao falar sobre motivos para o suicídio:

(...) desestrutura familiar também leva muito, você tá dentro de uma casa em que seu pai e sua mãe vivem se digladiando, então o adolescente sente... o que é que ele espera do futuro... nada, porque os pais são o espelho.

Nas palavras de Gilson, percebe-se que a dimensão temporal da existência pode vir a se caracterizar pela repetição, ou seja, a partir da convivência familiar (passado-que-vem-sendo) antecipa o futuro como prosseguimento da experiência atual. Heidegger (1927/2006) utiliza o termo cura para designar a totalidade da estrutura existen- cial do ser humano. A cura se manifesta individualmente ("empiricamente") como cuidado. Cura/cuidado não é um fenômeno relativo ao ‘ego', ao ‘eu’ ou ao ‘self', não se refere a uma instância intrapsíquica. O ser humano vive cuidando de seu ser, que é-no-mundo. "A vida como cuidar vive num mundo e cuida de si nos mais diversos modos de relações e execuções correspondentes (...) em função dos objetos que se encontram na experiência e dos próprios encontros" (Heidegger, 2011, p. 106). O cuidado é a relação que o homem tem com seu próprio ser: "Você vivencia sua vida como sendo sua e isso significa que quem você é faz diferença para você (é uma questão para você)" (Blattner, 2006, p. 48). Em sendo, o homem se preocupa com seu próprio ser (com sua vida). Nossa vida nos diz respeito, nos interessa, exige atenção, decisão. Blattner (2006) acrescenta: "ser uma pessoa é projetar uma pessoa para ser e então nosso ser é uma questão para nós” (p. 37).

Heidegger (1927/2006) afirma que "sendo em sua totalidade essencialmente indivisível, toda tentativa de reconstrução ou recondução do fenômeno da cura a atos ou impulsos particulares tais como querer ou desejar, propensão ou tendência acaba em fracasso" (p. 261). Ou seja, impulsos particulares são variações ou possibilidades individuais de realização da estrutura ontológica (geral) chamada cura. Quando o filósofo menciona a propensão, refere-se à propensão "para viver" (aspas no original, p. 263). Conforme Heidegger (1927/2006), a propensão para viver "tenta reprimir outras possibilidades" (p. 263). O autor não menciona o suicídio, porém, em se tratando de um fenômeno que mostra que o homem vive dando atenção ao seu próprio ser e o faz de diferentes maneiras, pode-se considerar que uma possibilidade que a propensão para viver reprime é a do suicídio.

O fenômeno do cuidado inclui as formas deficientes de cuidar, assim como o ser-com inclui a solidão. De acordo com Heidegger (2011) "esse cuidar está sempre numa diretiva determinada ou indeterminada, segura ou cambaleante" (p. 107; itálico no original). Somente quem dá atenção para seu próprio ser, para o modo como vive sua vida, pode desistir de ser. Por outro lado, negligenciar a própria vida, considerá-la irrelevante também são maneiras de estar em relação com o próprio ser. O descuido, o desinteresse, o desgosto pela vida são variações do fenômeno do cuidado. Ao contrário do que se possa pensar num primeiro momento, o suicídio não está fora da alçada do cuidado. O suicídio é uma possibilidade do cuidado. É uma possibilidade para um modo de ser que se relaciona consigo mesmo na forma de cuidado e que pode deixar de ser a qualquer momento, uma vez que já traz em si mesmo a possibilidade de seu fim.

Neste estudo, o suicídio, visto por parentes de suicidas do interior do Rio Grande do Norte e moradores das mesmas cidades e abordado à luz da Analítica Existencial de Martin Heidegger, aparece como um fenômeno caracterizado pela frustração. Para que alguém se frustre é necessário ser antecipando-se-a-si-mesmo, vislumbran- 
do possibilidades. Individualmente, algumas possibilidades são desejadas, são eleitas como sendo algo que se quer fazer, como objetivos pessoais. A realização de um objetivo pessoal gera uma expectativa. Expectativa diz respeito ao porvir, entretanto repercute na vida atual da pessoa, uma vez que aquilo que o ser humano ainda não é de fato, ele é existencialmente, pois a dimensão futura, o ainda-não (que pode ou não se realizar) é um constituinte do seu modo de ser (Heidegger, 1927/2006). O homem pode se frustrar porque o possível, como poder-ser, já está presente e repercute na disposição afetiva. $\mathrm{O}$ fracasso da realização das possibilidades é a frustração da expectativa e, digamos assim, gera uma contra-disposição. Em palavras simples, é o que é dito por Kátia, 17 anos, que, além de tentar o suicídio com medicamentos, era prima de um suicida:

Eu acho que uma pessoa daqui só tenta o suicídio quando ela não consegue o objetivo dela...

\section{Considerações finais}

A complexidade da questão do suicídio indica a necessidade de continuados estudos sobre o tema, a fim de que se possa conhecer diferentes contextos e circunstâncias de sua ocorrência, assim como diminuir o estigma associado ao fenômeno. O suicídio é um problema de saúde cujas origens não estão restritas ao que, genericamente, se chama de saúde mental. Entende-se aqui que a saúde é relativa ao ser humano e este não se restringe às suas características mentais. É necessário que se desenvolvam mais estudos sobre o fenômeno, levando em consideração esta visão ampliada e menos estigmatizante do suicídio.

A referência à Analítica Existencial de Heidegger permite relacionar o fenômeno específico (suicídio) com as estruturas existenciais que são sua condição de possibilidade, sem que isso implique numa abordagem mentalista internalizada, nem em relações mecânico-funcionais com o ambiente. Suicidar-se é possibilidade de um modo de ser que "tem em certa medida seu próprio ser na mão, à proporção em que se comporta de um modo ou de outro em relação ao seu poder-ser" (Heidegger, 2012, p. 401). Ou seja, lidar consigo próprio sabendo-se a caminho do futuro, porém não de um futuro que signifique apenas a passagem do tempo, repetindo, assim, o passado: um futuro que se torne presente como realização de projetos.

\section{Referências}

Aho, K. (2009). Heidegger's neglect of the body. Albany: State University of New York Press.

Alvarez, A. (1999). O Deus Selvagem: um estudo do suicídio. São Paulo: Companhia das Letras.
Bertolote, J. \& Fleischmann, A. (2002). A global perspective in the epidemiology of suicide. Suicidologi, Oslo, v. 7 n. 2, 6-8.

Blattner, W. (2006). Heidegger's Being and Time: a reader's guide. New York: Continuum.

Botega, N., Marin-León, L., Oliveira, H., Barros, M., Silva, V., \& Dalgalarrondo, P. (2009). Prevalência de ideação, plano e tentativa de suicídio: um inquérito de base populacional em Campinas, São Paulo, Brasil. Caderno Saúde Pública, Rio de Janeiro, 2632-2638.

Borges-Duarte, I. (2010). A fecundidade ontológica da noção de cuidado: de Heidegger a Maria de Lourdes Pintasilgo. Ex Aequo, 21, 115-131.

Cerel, J.; Jordan, J. \& Duberstein, P. (2008). The impact of suicide on the family. Crisis, 29(1), 38-44.

Durkheim, E. (1992). O suicídio. Estudo sociológico. Lisboa: Presença.

Dutra, E. (1997). Epidemiologia do suicídio no RN: 1985 a 1996. Anais da 50 Reunião da Sociedade Brasileira para o Progresso da Ciência, Natal, RN.

Dutra, E. (2002). A narrativa como uma técnica de pesquisa fenomenológica. Estudos de Psicologia (Natal), 7(2), 371-378.

Dutra, E. (2010). Suicídio no Brasil: estratégias de prevenção e intervenções. In Hutz, C. (Org.). Avanços em Psicologia Comunitária e intervenções psicossociais (p. 223-264). São Paulo: Casa do Psicólogo.

Heidegger, M. (2001). Seminários de Zollikon. Petrópolis: Vozes/ EDUC/ABD. (Originalmente publicado em 1987).

Heidegger, M. (2006). Ser e Tempo. Bragança Paulista: São Francisco, Petrópolis: Vozes. (Originalmente publicado em 1927).

Heidegger, M. (2011). Interpretações fenomenológicas sobre Aristóteles; introdução à pesquisa fenomenológica. Petrópolis: Vozes.

Heidegger, M. (2012). Os problemas fundamentais da fenomenologia. Petrópolis: Vozes.

Jamison, K. R. (2000). Night falls fast: understanding suicide. New York: Vintage Books.

Ministério da Saúde - Brasil (2006). Prevenção do suicídio: manual dirigido a profissionais das equipes de saúde mental. Disponível em http://bvsms.saude.gov.br/bvs/publicacoes/ manual_editoracao.pdf

Palhares, P. \& Bahls, S. (2003). O suicídio nas civilizações - Uma retomada histórica. Arquivos Brasileiros de Psiquiatria, Neurologia e Medicina Legal, 97 (84-85), 27-34.

Polt, R. (1999). Heidegger: an introduction. Ithaca: Cornell University Press.

Safranski, R. (2005). Heidegger, um mestre da Alemanha entre o bem e o mal. São Paulo: Geração Editorial.

Schmidt, M. (1990). A experiência de psicólogos na comunicação de massa. Tese de Doutorado. Instituto de Psicologia. 
Universidade de São Paulo, São Paulo, Brasil.

Serra, J. (2008). O suicídio como uma das belas artes. Covilhã: LusoSofia Press.

Sheehan, T. (1995). Heidegger's new aspect. Research in Phenomenology, 25, 207-225.

Vattimo, G. (1987). Introdução a Heidegger. Rio de Janeiro: Edições 70. (Originalmente publicado em 1971).

WHO, World Health Organization. (2014). Preventing suicide: a global imperative. Disponível em: <http:/www.who.int/ mental_health/suicide-prevention/world_report_2014/en/>.

Marcelo Vial Roehe - Graduado em Psicologia pela Universidade Federal do Rio Grande do Sul, Mestre em Psicologia pela Pontifícia Universidade Católica do Rio Grande do Sul e Doutor em Psicologia pela Universidade Federal do Rio Grande do Norte. Atualmente é Professor da Universidade Federal do Sul e Sudeste do Pará, Marabá. Endereço Institucional: Universidade Federal do Sul e Sudeste do Pará (UNIFESSPA). Av. dos Ipês, s/n, Cidade Jardim, Marabá/PA. CEP: 68.500-000. E-mail: mvroehe@gmail.com

Elza Dutra - Possui graduação em Psicologia pela Universidade Católica de Pernambuco, Mestrado em Psicologia Escolar pela Universidade Gama Filho e Doutorado em Psicologia Clínica pela Universidade de São Paulo. Atualmente é Professora Titular de Psicologia Clínica Fenomenológica na Universidade Federal do Rio Grande do Norte e Pós-Doutora pela Universidade Federal Fluminense. Docente-pesquisadora do PPgPsi, orientadora de Mestrado e Doutorado. Coordenadora do Grupo de Estudos Subjetividade e Desenvolvimento Humano - GESDH/UFRN/ CNPq. Coordenadora do GT - Psicologia \& Fenomenologia - ANPEPP (2014-2016) e Vice-coordenadora (2016-2018).

Recebido em 16.03.2016 Primeira Decisão Editorial em 18.10.2016 Aceito em 04.11.2016 